\title{
An Efficient Method for Electrical Earth Resistance Reduction Using Biochar
}

\author{
Lukong Pius Nyuykonge ${ }^{1, \text { * }}$, Noël Djongyang ${ }^{1}$, Lendzemo Wirnkar Venasius ${ }^{2}$, Fagbenro John Adeneyi ${ }^{3}$ \\ ${ }^{1}$ Department of Renewable Energy, The Higher Institute of the Sahel, University of Maroua, Maroua, Cameroon \\ ${ }^{2}$ Institute of Agricultural Research for Development (IRAD-Bambui), Bamenda, Cameroon \\ ${ }^{3}$ Department of Crop Production, Soil and Environmental Management, Bowen University, Iwo, Osun State, Nigeria \\ Email address: \\ lukongpius2007@gmail.com (L. P. Nyuykonge), noeldjongyang@gmail.com (N. Djongyang), vlendzemo@hotmail.com (L. W. Venasius), \\ pastfagbenro@yahoo.com (F. J. Adeneyi)
}

\section{To cite this article:}

Lukong Pius Nyuykonge, Noël Djongyang, Lendzemo Wirnkar Venasius, Fagbenro John Adeneyi. An Efficient Method for Electrical Earth Resistance Reduction Using Biochar. International Journal of Energy and Power Engineering. Vol. 4, No. 2, 2015, pp. 65-70.

doi: $10.11648 /$ j.ijepe.20150402.17

\begin{abstract}
This paper presents a method that treats the soil by replacing a volume of the earthing portion with biochar instead of chemicals. The method contributes to reduce the earth resistance over long periods of time in order to avoid the expensive cost of these elements and their secondary effects. In the proposed method, a volume of soil from an earthing portion of $20 \mathrm{~cm}$ in diameter and $1 \mathrm{~m}$ deep is replaced with dry biochar. The earthing electrode is driven into this earthing portion. The use of this method significantly reduced the earth resistance with one electrode from $242.0 \Omega$ to an average of $26.27 \Omega$ with the Clay sandy soils of the Sahelian zone of Cameroon during the dry season and $2.1 \Omega$ during the rainy season. Furthermore, smaller reductions were achieved when connecting the two such earths in parallel reducing the resistance of clay-sandy soils from $242.0 \Omega$ to $15.2 \Omega$ in the dry season and $1.1 \Omega$ during the raining season.
\end{abstract}

Keywords: Earth Resistance, Earthing Portion, Chemicals, Biochar

\section{Introduction}

To ensure the safety of persons and electrical equipment, efficient and sustainable earthing systems have to be installed in both commercial and residential buildings. Deep-driving of electrodes, installation of Ufer grounds and backfilling are methods generally used. The first method has not been viable when the layer of soil at grounding site is very thin. In such a condition, backfilling becomes more preferable. The use of chemicals like Bentonite, Dead sea water, etc. around the electrode of earthing systems has proved to reduce the earth resistance improving the efficiency of these systems. However, the use of these chemicals can't achieve very small earth resistance for a long time especially in the case of dry clay and dry sandy soils. Secondly, they are not only expensive but also not available everywhere and all the time. Some are corrosive and some easily leached.

An electrical grounding system is a path way which discharge naturally occurring charges like the immense amount of lightning charge or charges in electrical systems to the earth's crust within as short a time as possible. Poor considerations and designs failure has often let to many electrical shock accidents. As a result of these accidents research on earthing systems have always been given much considerations [1]. Good earthing systems reduce the results of damages and maintain high reliability of devices caused by lightning or fault currents [2, 3]. To reach good grounding system, the resistance in ohm between the grounding electrode and the earth has to be relatively small. As it decreases, the grounding connection improves. This resistance refers to earth resistance. The accepted value of the earth resistance differs from applications to applications. Some of them accept earth resistance of $25 \mathrm{ohm}$ or less whereas others accept it of $3 \mathrm{ohm}$ or less. In the case of earth fault conditions, the low earth resistance enables the protection system to isolate the power source and makes the earth potential rise (EPR) less dangerous to humans $[4,5]$. To improve the personal safety, the equipment protection and to maintain the continuity of the power supply, buildings have to be provided by such systems $[6,7]$. These systems provide alternative and low resistance path for leakage or faulty current to flow [8]. It protects buildings from the effect of lightning and reduces the electromagnetic disturbances. Also, it is used as a reference 
voltage in case of measurements. Recently, a number of earthing systems have been proposed to improve the grounding connection efficiency [9-11]. To reduce the earth resistance, chemical elements are added to the soil around the electrode [12]. However, these elements are expensive and sometimes can't ensure good grounding connection for a long period of time [13]. In 2014, another method was proposed, reducing the earth resistance with the use of Dead sea water [14]. This previous method has proved to realise good reductions, however the Dead Sea water has to be renewed every two years according to the porosity of the ground and the amount of rain. This limits the application of Dead Sea water as it may not be suitable for very dry soils like the Sudano-Sahelian soils of Africa. Moreover, the chemical elements in either Bentonites or Dead sea water are susceptible to leaching and oxidation which may lead to corrosion of grounding electrodes. Biochar has been investigated as one of the elements for soil treatment. Biochar is a fine-grained charcoal-like material that is produced through the heating of biomass under air-deprived conditions. This process is called pyrolysis. A wide variety of organic matter sources can be used as a feedstock for this process, including residues from forests or crop production, from animal production (manures), and from green waste streams, such as yard wastes [15]. Biochar has a high tendency to absorb and retain water, has a lot of pores most of which are coated with mineral ions which can be easily modified during production of biochar increasing its conductivity. Finally biochar can last in soils for hundreds of years before losing the role in soil enhancement. These properties makes it desirable for applications in grounding system improvement as they could result in lowering as well as minimizing the fluctuation of ground resistance over a long period of time. The conclusion that biochar is long-lived is supported by Bird et al, [16,17,18].who found that a component of charred material is highly oxidation resistant under laboratory treatment both with acid dichromate and basic peroxide. The fraction of biochar that will exhibit such oxidation resistance will of course depend upon both the feedstock and pyrolysis conditions. These observations do not, however, rule out the possibility that char may decompose more rapidly in other environments. According to Jones [19], optimal ground improvement materials for reduction of earth resistance possess the following characteristics:

- Compactable and soil-compacting

- Naturally inert

- Have low and stable resistivity

- Able to maintain low grounding resistance with minimal fluctuation for long period of time

- Does not leaches with time

- Economically viable.

Furthermore, biochar is said to have ameliorated the physical and chemical properties of [20-21]. Little is published on the electrical conductivity of biochar However, the report presenting biochar as a Super capacitor electrode [22], shows that biochar possess a reliable degree of electrical conductivity based on biomass substrate which could be exploited for different applications. In this paper, an earthing system that uses biochar instead of Bentonite or Dead Sea water is proposed.

\section{An Overview of Earth Resistance Measurements Without Soil Treatment}

In our experiments, the 3-pole-fall-of-potential method was used to measure the dissipation capability of a single ground electrode, two parallel ground electrodes in sandy clay soils at the Renewable Energy laboratory of the University of Maroua, as well as laterite soils in the Centre region tested at the sites of the National Electricity Company ENEO. An electrode of 120 $\mathrm{cm}$ length, diameter of $1 \mathrm{~cm}$, steel-galvanized copper was used to connect devices with the earth. Also, two assistant electrodes $\mathrm{C}$ and $\mathrm{P}$ are used. These assistant electrodes were put at suitable distance from earth electrode $\mathrm{E}$ which is needed to measure the earth resistance as in figure 1.

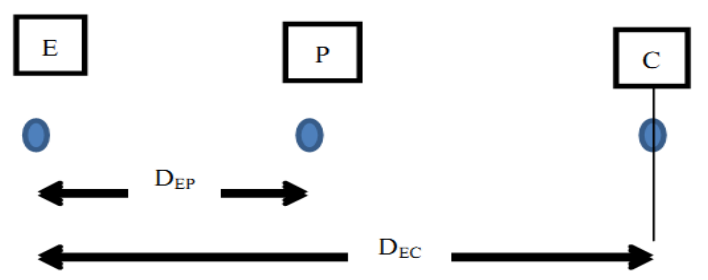

Figure 1. Reference of Distances for measurements based on the manual for VOLTCRAFT multimeter (CAT III 600V, ET-02) earth tester.

The assistant electrodes length was of $30 \mathrm{~cm}$ and the distance between $\mathrm{E}$ and $\mathrm{P}$ was at least 20 meters. Note that the soil of our experiment is a dry mixture of sand and clay. The electrode was inserted into the ground at varied depths $(40,80$, $100 \mathrm{~cm})$. The distance between the electrode $\mathrm{E}$ and $\mathrm{C}$, the furthest point was noted $\mathrm{D}_{\mathrm{EC}}(20 \mathrm{~m})$ that between $\mathrm{E}$ and $\mathrm{P}$, the varying distance was noted $\mathrm{D}_{\mathrm{EP}}$ which was varied at $52 \%$, $62 \%$ and $72 \%$ of $\mathrm{D}_{\mathrm{EC}}$ as demonstrated in the setup below.

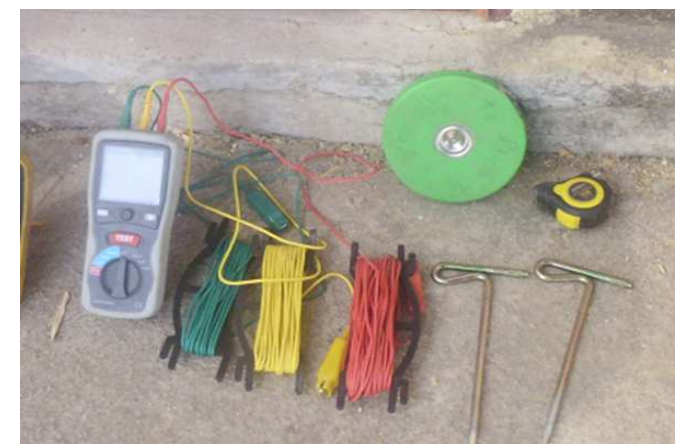

Figure 2. VOLTCRAFT CATT III Digital earth tester with connection cables.

The VOLTCRAFT multimeter (CAT III 600V, ET-02) (Fig.

2) used to measure the soil resistance has the following characteristics:

-2 pole and 3 pole methods,

-Measurement range 0.01 to $2000 \Omega$,

-Measuring Frequency $128 \mathrm{~Hz}$,

-Confirmation of the measurement by self-diagnosis,

-3 fault presence indicators to validate measurements, 
-Colour-coded terminals for connecting rods,

-Protection by HRC fuse,

-Leak proof on-site casing,

Devices such as Wires, shovel, Hammer, pair of pincers were used.

\subsection{Earth Resistance Based on Single Electrode Without Soil Treatment}

Here we drilled the grounding electrode into the earthing portion. The drilling was done using the hammer as shown in the model below (fig. 3).

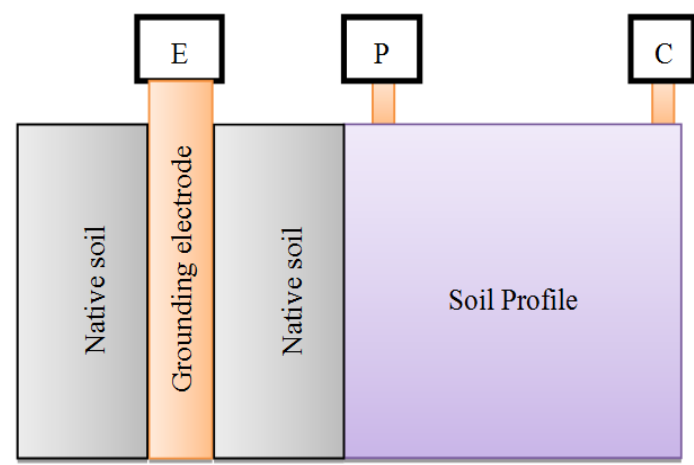

Figure 3. Setup designed to measure soil resistance with VOLTCRAFT CATT III Digital earth tester based on one electrode.

Caution was taken as in the VOLTCFAFT manual especially the use of water to moist the ground at $\mathrm{P}$ and $\mathrm{C}$ so as to ensure proper contacts with the ground. The point $\mathrm{C}$ was taken as $20 \mathrm{~m}$ and $\mathrm{P}$ was varied at $52 \%(10.4 \mathrm{~m}), 62 \%(12.4 \mathrm{~m})$ and $72 \%(14.4 \mathrm{~m})$ of $\mathrm{D}_{\mathrm{EC}}(20 \mathrm{~m})$ for each depth of the electrode varied at 40,80 and $100 \mathrm{~cm}$. The resistance was then noted on the screen of the earth tester.

\subsection{Earth Resistance Based on Parallel Two Rods Without Soil Treatment}

Here we drilled two similar electrodes at $2.4 \mathrm{~m}$ of the same characteristics using the hammer. An earthing cable of 16 $\mathrm{mm}^{2}$ was used to interconnect the two electrodes, and then the resistance was measured as shown in the model below (fig. 4).

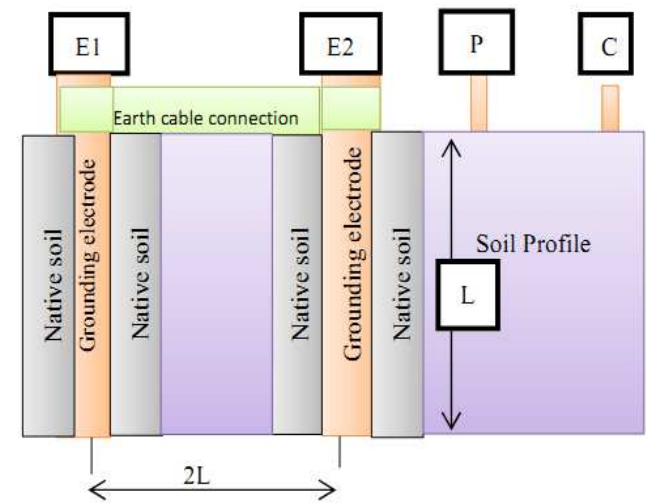

Figure 4. Setup designed to measure soil resistance with VOLTCRAFT CATT III Digital earth tester based on two electrodes.
The point $\mathrm{C}$ was taken as $20 \mathrm{~m}$ from $\mathrm{E} 2$ and $\mathrm{P}$ was varied at $52 \%(10.4 \mathrm{~m}) 62 \%(12.4 \mathrm{~m})$ and $72 \%(14.4 \mathrm{~m})$ of $\mathrm{D}_{\mathrm{EC}}(20 \mathrm{~m})$ for each depth of the electrode varied at 40,80 and $100 \mathrm{~cm}$. The resistance was then noted on the screen of the earth tester.

\section{Proposed Method for Soil Resistance Reduction Using Biochar}

A cylindrical hole of $20 \mathrm{~cm}$ in diameter and $1 \mathrm{~m}$ deep is dug and the soil from this hole is replaced with biochar. Before the replacement, some water is sprayed within the walls just to wet the walls before filling biochar. This is to ease contact between the biochar and native soil. This if followed by compacting the biochar into the hole. We rely on the fact that biochar has a lower resistance as it contains a lot of mineral salts (table 1) and will last as long as hundreds of years from previous studies., Biochar is cheap as its raw material (biomass), mostly waste is found ever where in the world and it's conversion and storage in this form will be another strategy to mitigate climate change by storing of carbon, it's main element. Application of biochar over years will not be necessary as in the case of Dead Sea water.

Table 1. Concentration of a number of elements in 3 different biochar produced at $500^{\circ} \mathrm{C}[23]$.

\begin{tabular}{|c|c|c|c|c|}
\hline Element & Unit & $\begin{array}{l}\text { Neem } \\
\text { Biochar }\end{array}$ & $\begin{array}{l}\text { Rice straw } \\
\text { Biochar }\end{array}$ & $\begin{array}{l}\text { Wood chip } \\
\text { biochar }\end{array}$ \\
\hline $\mathrm{pH}$ & - & $9.8(\mathrm{H} 2 \mathrm{O})$ & $9(\mathrm{CaCl} 2)$ & $9.2(\mathrm{H} 2 \mathrm{O})$ \\
\hline $\mathrm{C}_{\text {org }}$ & $\%$ & 48 & 44 & 23.61 \\
\hline $\mathrm{C}_{\text {total }}$ & $\%$ & 48 & 44 & 56 \\
\hline $\mathrm{N}_{\text {total }}$ & $\%$ & 5.46 & 1.1 & 1.06 \\
\hline O.M & $\%$ & - & - & 40.71 \\
\hline$P_{\text {total }}$ & $\%$ & 45.97 & - & 0.684 \\
\hline $\mathrm{Ca}$ & $\%$ & 0.65 & 4.6 & 30.49 \\
\hline $\mathrm{Mg}$ & $\%$ & 0.56 & 0.49 & 3.68 \\
\hline $\mathrm{Na}$ & $\%$ & 4.05 & 0.060 & 6 \\
\hline K & $\%$ & 2.24 & 1.9 & 1.27 \\
\hline $\mathrm{Fe}$ & $\mathrm{mg} / \mathrm{kg}$ & 713.0 & 290.0 & 5469.58 \\
\hline $\mathrm{Cu}$ & $\mathrm{mg} / \mathrm{kg}$ & 13.00 & 7.2 & 0 \\
\hline $\mathrm{Zn}$ & $\mathrm{mg} / \mathrm{kg}$ & 185.30 & 71 & 93.83 \\
\hline $\mathrm{Pb}$ & $\mathrm{mg} / \mathrm{kg}$ & 0.19 & 4.6 & 0 \\
\hline $\mathrm{Cd}$ & $\mathrm{mg} / \mathrm{kg}$ & - & $<0.3$ & 0 \\
\hline $\mathrm{Cr}$ & $\mathrm{mg} / \mathrm{kg}$ & 0.03 & 8.9 & 0 \\
\hline $\mathrm{Ni}$ & $\mathrm{mg} / \mathrm{kg}$ & 40.33 & 2.8 & 47.12 \\
\hline $\mathrm{Mn}$ & $\mathrm{mg} / \mathrm{kg}$ & 175.16 & 120 & 0 \\
\hline $\mathrm{S}$ & $\%$ & - & 0.12 & - \\
\hline Molybdenum & $\mathrm{mg} / \mathrm{kg}$ & - & 0.43 & - \\
\hline Boron & $\mathrm{mg} / \mathrm{kg}$ & - & 52 & - \\
\hline Arsenic & $\mathrm{mg} / \mathrm{kg}$ & - & $<5$ & - \\
\hline Aluminium & $\%$ & - & 0.36 & - \\
\hline
\end{tabular}




\subsection{Earth Resistance Based on One Electrode with Biochar} Treatment

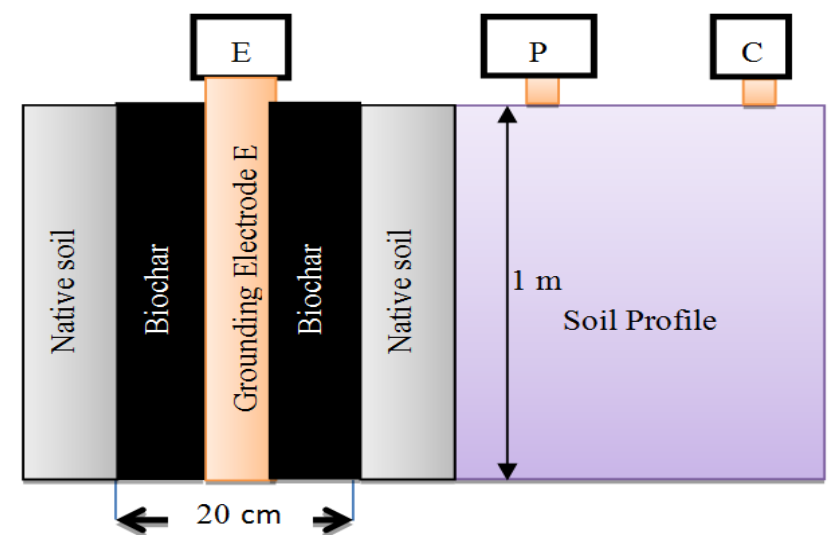

Figure 5. Setup designed to measure soil resistance with VOLTCRAFT CATT III Digital earth tester based on two electrodes with biochar treatment.

Again the same procedure is followed but this time the electrode is driven into biochar earthing portion to a constant depth of $1 \mathrm{~m}$. Make sure the biochar is dry before concluding the test. Figure 5 shows the setup designed to measure soil resistance based on two electrodes with biochar treatment while Figure 6 shows how the soil was treated during the experiment with biochar used in its dry conditions.

The point $\mathrm{C}$ was taken as $20 \mathrm{~m}$ and $\mathrm{P}$ was varied at $52 \%$ $(10.4 \mathrm{~m}) 62 \%(12.4 \mathrm{~m})$ and $72 \%(14.4 \mathrm{~m})$ of $\mathrm{D}_{\mathrm{EC}}(20 \mathrm{~m})$ for the depth of $1 \mathrm{~m}$.

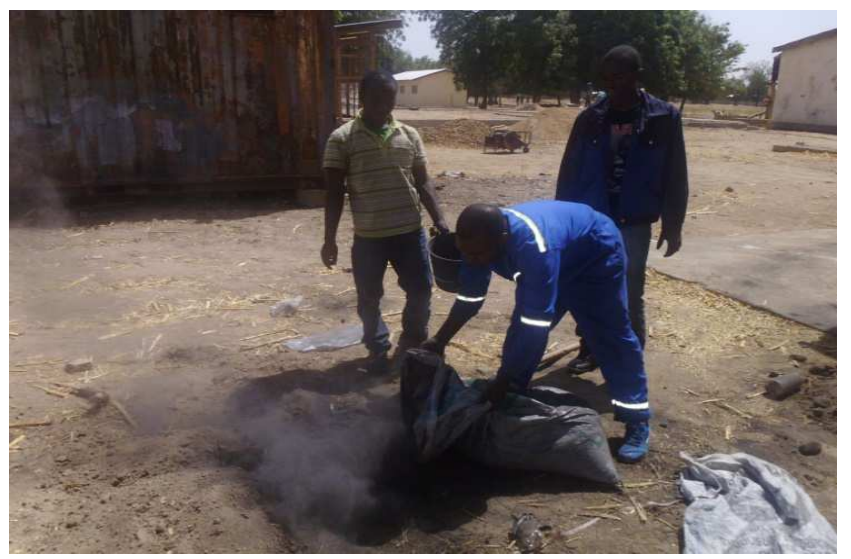

Figure 6. Soil in Grounded portion replaced with biochar.

\subsection{Earth Resistance Based on Two Parallel Electrodes with Biochar Treatment}

In the same manner, two similar electrodes at $2.4 \mathrm{~m}$ of the same characteristics using the hammer (figure 7). An earthing cable of $16 \mathrm{~mm}^{2}$ was used to interconnect the two electrodes, and then the resistance was measured as shown in the model below. Measurements were carried out at several periods of the days, with the (clay-sandy) soils very dry.

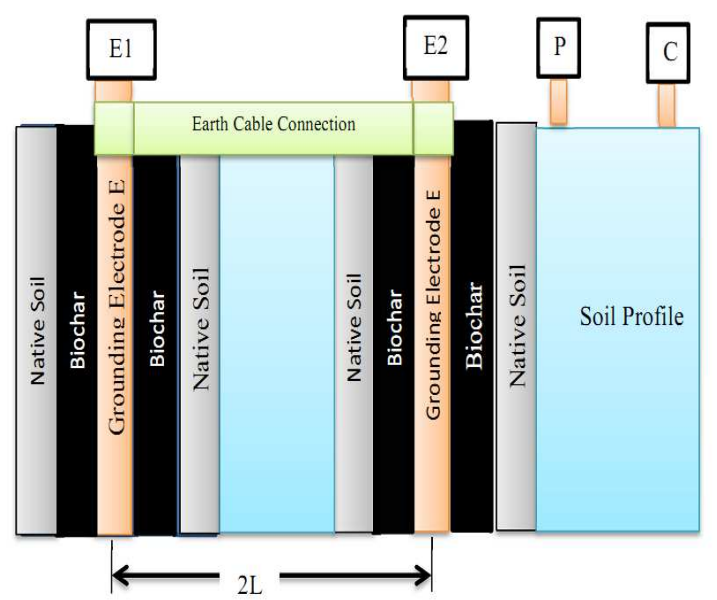

Figure 7. Setup designed to measure soil resistance with VOLTCRAFT CATT III Digital earth tester based on two electrodes with biochar treatment.

The point $\mathrm{C}$ was taken as $20 \mathrm{~m}$ from $\mathrm{E} 2$ and $\mathrm{P}$ was varied at $52 \%(10.4 \mathrm{~m}) 62 \%(12.4 \mathrm{~m})$ and $72 \%(14.4 \mathrm{~m})$ of $\mathrm{D}_{\mathrm{EC}}(20 \mathrm{~m})$. The resistance was then noted on the screen of the earth tester.

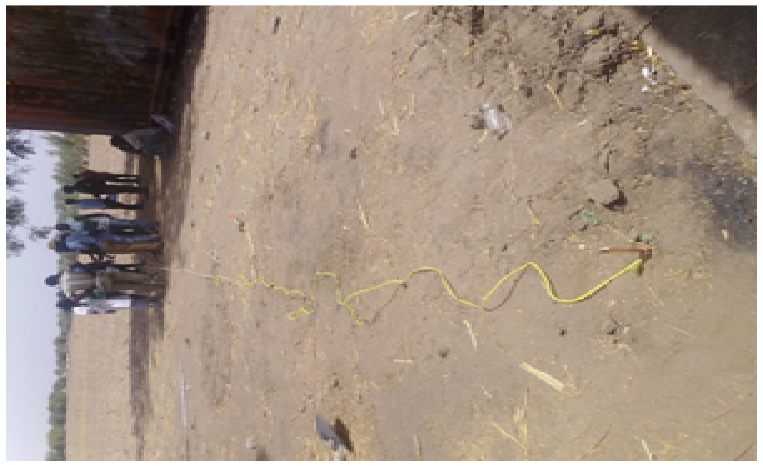

Figure 8. Two Grounded portions connected in parallel.

Figure 8 shows two grounded portions connected in parallel during the experiment.

\section{Experimental Results and Discussions}

\subsection{Earth Resistance Without Soil Treatment}

\subsubsection{Earth Resistance Based on Single Rode Without Soil Treatment}

Table 2. Measured earth resistance at a distance $D_{E P}=52 \% D_{E C}$.

\begin{tabular}{ll}
\hline Depth of electrode $(\mathbf{m})$ & Measured earth resistance $(\mathbf{\Omega})$ \\
\hline 0.4 & 300.8 \\
0.8 & 268.0 \\
1.0 & 242.0 \\
\hline
\end{tabular}

Table 3. Measured earth resistance at a distance $D_{E P}=62 \% D_{E C}$.

\begin{tabular}{ll}
\hline Depth of electrode $(\mathbf{m})$ & Measured earth resistance $(\mathbf{\Omega})$ \\
\hline 0.4 & 288.4 \\
0.8 & 142.2 \\
1.0 & 122.4 \\
\hline
\end{tabular}


Table 4. Measured earth resistance at a distance $D_{E P}=72 \% D_{E C}$.

\begin{tabular}{ll}
\hline Depth of electrode $(\mathbf{m})$ & Measured earth resistance $(\mathbf{\Omega})$ \\
\hline 0.4 & 298.7 \\
0.8 & 130.2 \\
1.0 & 128.2 \\
\hline
\end{tabular}

It could be seen from tables 2 to 4 that the Earth resistance is reduced while driving the electrodes deeper into the earth. This could be as a result of increase in effective contact area between the electrode and the earth. Again, humidity increases with increase in depth in the soil profile.

\subsubsection{Earth Resistance Based on Two Parallel Electrodes Without Soil Treatment}

Table 5. Measured earth resistance at a distance $D_{E P}=52 \% D_{E C}$.

\begin{tabular}{ll}
\hline Depth of electrode $(\mathbf{m})$ & Measured earth resistance $(\mathbf{\Omega})$ \\
\hline 0.4 & 92.5 \\
0.8 & 52.6 \\
1.0 & 48.2 \\
\hline
\end{tabular}

Table 6. Measured earth resistance at a distance $D_{E P}=62 \% D_{E C}$.

\begin{tabular}{ll}
\hline Depth of electrode $(\mathbf{m})$ & Measured earth resistance $(\mathbf{\Omega})$ \\
\hline 0.4 & 93.8 \\
0.8 & 58.2 \\
1.0 & 48.1 \\
\hline
\end{tabular}

Table 7. Measured earth resistance at a distance $D_{E P}=72 \% D_{E C}$.

\begin{tabular}{ll}
\hline Depth of electrode $(\mathbf{m})$ & Measured earth resistance $(\mathbf{\Omega})$ \\
\hline 0.4 & 98.9 \\
0.8 & 54.1 \\
1.0 & 48.0 \\
\hline
\end{tabular}

From the above tables (5 to 7 ), one can see that the Increase in the Number of electrodes decreases the soil resistance. This is however, limited to a certain number with respect to the system's point of saturation, available space for groundings and cost. The decrease in resistance could be as a result of increase in the total contact area increasing the tendency of electron motion within the Electron-Ground interface which in effect also greatly improved the surge impedance of the grounding system due to the large capacitive coupling which is achieved. This could also be explained by the laws of electricity related to equivalent resistance when in parallel.

\subsection{Earth Resistance with Soil Treatment}

\subsubsection{Earth Resistance Based on One Electrode with Biochar Soil Treatment Under Very Dry Conditions (Far North Region, Cameroon)}

Table 8. Measured earth resistance with addition of biochar at electrode depth of $1 \mathrm{~m}$.

\begin{tabular}{ll}
\hline Distance $\mathbf{D}_{\mathrm{EP}}$ & Measured earth resistance $(\mathbf{\Omega})$ \\
\hline $52 \% \mathrm{D}_{\mathrm{EC}}$ & 26.24 \\
$62 \% \mathrm{D}_{\mathrm{EC}}$ & 26.20 \\
$72 \% \mathrm{D}_{\mathrm{EC}}$ & 26.42 \\
Average & 26.27 \\
\hline
\end{tabular}

One could easily check from table 8 that the earth resistance with biochar dropped significantly with little variations while varying the measuring probe $P$. This can be explained with the fact that biochar had enhanced the earthing portion of the soil, making it more electrically conductive. This could also have been influenced by the physical characteristics of biochar i.e. porous nature, conductive metal elements around pores, and high degree of compaction amongst many.

\subsubsection{Earth Resistance Based on Two Electrodes with Biochar Soil Treatment under Very Dry Conditions (Far North Region, Cameroon)}

Table 9. Measured earth resistance based on two electrodes with addition of biochar at electrode depth of $1 \mathrm{~m}$.

\begin{tabular}{ll}
\hline Depth of electrode $(\mathbf{m})$ & Measured earth resistance $(\mathbf{\Omega})$ \\
\hline $52 \% \mathrm{D}_{\mathrm{EC}}$ & 15.2 \\
$62 \% \mathrm{D}_{\mathrm{EC}}$ & 15.4 \\
$72 \% \mathrm{D}_{\mathrm{EC}}$ & 15.0 \\
Average & 15.2 \\
\hline
\end{tabular}

From table 9, it could be seen that the earth's Resistance dropped further by connecting the electrodes in parallel. However, the reduction is not very significant compared to that without soil treatment. The values obtained do not vary much. This could be explained by the fact that with biochar as a foreign compound in a particular portion of the soil, the electric fields must have been altered in a manner that needs to be explained in further work.

\subsubsection{Earth Resistance Based on Two Electrodes with Biochar Soil Treatment Under Wet Conditions (Far North Region, Cameroon) During Rainy Season}

Table 10. Measured earth resistance based on two electrodes with addition of biochar at electrode depth of $1 \mathrm{~m}$ under wet (rainy season) conditions.

\begin{tabular}{ll}
\hline Depth of electrode $(\mathbf{m})$ & Measured earth resistance $(\boldsymbol{\Omega})$ \\
\hline $52 \% \mathrm{D}_{\mathrm{EC}}$ & 1.0 \\
$62 \% \mathrm{D}_{\mathrm{EC}}$ & 1.2 \\
$72 \% \mathrm{D}_{\mathrm{EC}}$ & 1.0 \\
Average & 1.1 \\
\hline
\end{tabular}

The earth resistance is reduced significantly and remains the same for a long time even two months after the rainy season. This could be as a result of the fact that biochar has a high capacity for water retention and does not leach. Biochar is said to last in soils for hundreds of years, still retaining their soil enhancement properties with a high degree of stability with respect to oxidation. However, biochar properties vary with substrate and pyrolysis conditions as shown previously in table 1 .

\section{Conclusion}

The application of biochar as an efficient method for earth resistance reduction was investigated in this study. Analysis of experimental results show that a significant reduction in the earth resistance was obtained with biochar obtained from rice straw compared to the case without soil treatment. The results of different experiments conducted on both treated 
and untreated soils show indeed that biochar is an efficient chemical for the reduction of electrical soil resistance. However, there is the need to replicate the study in other grounding system installations before conclusions can be drawn. Also, various issues relating to the use of biochar as ground improvement material need to be studied; especially the stability of the biochar with respect to conductivity. The quantity of biochar for optimum reductions needs to be studied as well. Watered grounds at longer time intervals could achieve very low resistance in dry places like the deserts. Furthermore, biochar electrical conductivity could be increased by spraying soluble salts or solutions of clay during its production to increase its mineral concentration. Watered grounds at longer time intervals could achieve very low resistance in dry places like the deserts. Furthermore, biochar electrical conductivity could be increased by spraying soluble salts or solutions of clay to increase its mineral concentration.

\section{References}

[1] Hammuda1, A., Nouri, H. and Al-Ayoubi, M. (2011). An Investigation into Substation Grounding and Its Implementation on Gaza Substation. Energy and Power Engineering, 3, 593-599.

[2] Kinsler, M. (1998). A Damage Mechanism: Lightning-Initiated Fault-Current Area to Communication Cables Buried Beneath Overhead Electric Power Lines. IEEE Industrial and Commercial Power Systems Technical Conference, 109-118.

[3] Na, J., Kang, H., Kim, Y., Chang, K., Hwang, Y. and Ko, T. (2011). Experimental Study on the Lightning Impulse Dielectric Characteristics of Sub-Cooled Liquid Nitrogen for a High Voltage Superconducting Fault Current Limiter. IEEE Transactions on Applied Superconductivity, 21, 1336-1339. http://dx.doi.org/10.1109/TASC.2011.2105456

[4] Dusang, L.V. (2008). A Ground Fault Protection Method for Ungrounded Systems. IEEE Electric Power Conference EPEC, $1-6$.

[5] Ferrell, B. and Ostdyk, R. (2010). Modeling and Performance Considerations for Automated Fault Isolation in Complex Systems. IEEE Aerospace Conference, 1-8.

[6] Kamel, R., Chaouachi, A. and Nagasaka, K. (2011). Comparison the Performances of Three Earthing Systems for Micro-Grid Protection during the Grid Connected Mode. Smart Grid and Renewable Energy, 2, 206-215. http://dx.doi.org/10.4236/sgre.2011.23024

[7] Colominas, I., Gómez-Calviño, J., Navarrina, F. and Casteleiro, M. (2001). Computer analysis of Earthing Systems in horizontally or vertically Layered Soils. Electric Power $\begin{array}{lll}\text { Systems } & \text { Research, } & \text { 149-156. }\end{array}$ http://dx.doi.org/10.1016/S0378-7796(01)00148-1

[8] Shalash, N., Haidar, A. and Abdul Sattar, K. (2012) Grounding Locations Assessment of Practical Power System. Energy and $\begin{array}{lll}\text { Power } & \text { Engineering, } & \text { 19-27. }\end{array}$ http://dx.doi.org/10.4236/epe.2012.41003 [9] Roberts, J. and Aituve, J. (2001). Review of Ground Fault Protection Methods for Grounded, Ungrounded, and Compensated Distribution Systems, SEL.

[9] John A. Fagbenro, Suarau O. Oshunsanya and Bolarinwa A. Oyeleye. Effects of Gliricidia Biochar and Inorganic Fertilizer on Moringa Plant Grown in an Oxisol. Communications in Soil Science and Plant Analysis $00: 1-8,2015$.

[10] Hanninen, S. (2001) Single Phase Earth Faults in High Impedance Grounded Networks Characteristics, Indication and Location. Valtion Teknillinen Tutkimuskeskus Technical Research Centre of Finland, Espoo.

[11] Kojovic, L.A., Day, T.R. and Chu, H.H. (2003). Effectiveness of Restricted Ground Fault Protection with Different Relay Types. Power Engineering Society General Meeting, IEEE, 13-17 July 2003, 1-6.

[12] Jinxi, M. and Dawalibi, F.P. (2006) Grounding Analysis of a Large Electric Power Station. IEEE International Conference on Power System Technology, Chongqing, 22-26 October 2006, $1-6$.

[13] Jacob, D. and Nithiyananthan, K. (2008). Effective Methods for Power Systems Grounding. WSEAS Transactions on Business and Economics, 5, 151-160.

[14] El-Tous, Y. and Alkhawaldeh, S.A. (2014). An Efficient Method for Earth Resistance Reduction Using the Dead Sea Water. Energy and Power Engineering, 6, 47-53.

[15] Lehmann J and Joseph S (2009). Biochar for Environmental Management: Science and Technology. Earthscan Ltd, London, UK, $404 p$

[16] Bird M. I. and Gro cke D. R. (1997). Determination of the abundance and carbon isotope composition of elemental carbon in sediments. Geochim. Cosmochim. Acta 61, 3413-3423.

[17] Bird M. I. and Cali J. A. (1998). A million-year record of fire in sub- Saharan Africa. Nature 394 , 767-769.

[18] Bird M. I., Moyo C., Veenendaal E. M., Lloyd J. and Frost P. (1999). Stability of elemental carbon in savanna soil. Global Biogeochem. Cycles 13 , 923-932

[19] W. R. Jones, IEEE Transactions on Power Apparatus and Systems, PAS-99 (1980),

[20] Glaser, B., Lehmann, J., Zech, W. (2002). "Ameliorating physical and chemical properties of highly weathered soils in the tropics with charcoal - a review", Biology and Fertility of Soils 35: 4

[21] Zeeshan A., et al. (2014). Impact of Biochar on Soil Physical Properties. Agricultural Sciences, Vol. 4(5), pp. 280-284 May, 2014. http:// www.scholarly-journals.com/SJAS

[22] Junhua, J. et al. (2012). Biochar Supercapacitor Electrodes. Illinois Biochar Group Meeting, June 14, 2012.

[23] Lukong Pius Nyuykonge (2014). Biochar Production and Analysis for Soil Enhancement and Climate Change Mitigation. M.Eng. Thesis. University of Maroua: Cameroon. 